\title{
Listening to Young Children: Applying Montessori's Method to English as an Additional Language (EAL) Education
}

\author{
Carla Briffett Aktaş \\ Department of Educational Research, Lancaster University, Lancaster, UK
}

Email address:

c.briffett@lancaster.ac.uk

To cite this article:

Carla Briffett Aktaş. Listening to Young Children: Applying Montessori's Method to English as an Additional Language (EAL) Education. International Journal of Elementary Education. Vol. 6, No. 1, 2017, pp. 1-7. doi: 10.11648/j.ijeedu.20170601.11

Received: December 27, 2016; Accepted: January 25, 2017; Published: February 10, 2017

\begin{abstract}
Increasing globalization means that many families are moving into English speaking environments, and so too are their young children. To date, research on English as an Additional Language (EAL) education has largely been focused on primary, secondary, and post-secondary schooling. EAL research should include preschool aged children, since this group is also a part of the globalization trend. Likewise, discourse in education surrounding social justice has largely focused on older student groups. Here, the focus is on preschool aged children, bridging the gap between globalization, EAL education, and social justice disciplines. The action research conducted here employed the Montessori Method to promote a socially just learning environment for young preschool EAL children that focused primarily on experiential learning. Data analysis of the Teaching English to Speakers of Other Languages (TESOL) checklists, used to monitor language progress, indicates that such an educational pedagogy has a positive outcome for English development when social justice is placed in a prominent role in the education process. The education being provided in this study sought to establish that socially just EAL education can be provided, but that the educator must take on the role of a listener in order for this educational model to be successful. This application seeks to give even the youngest of students a voice in their education, without jeopardizing the rate at which English is acquired.
\end{abstract}

Keywords: Social Justice, English as an Additional Language (EAL), Montessori Method, Early Childhood Education (ECE)

\section{Introduction}

Globalization is an increasingly common trend throughout the world and has been the subject of dialogue and examination by the academic community in varying disciplines [1-5]. With this trend comes the need for English as an Additional Language (EAL) education. Even for those children who live in non-English speaking societies, English education may still be needed for further opportunities in schooling and later, in professional life.

Discourse among educators stresses the need for socially just education, but the literature on social justice and student voice tends to focus on older student groups and does not account for young EAL students [6-8]. Similarly, research conducted in EAL education does not address the English language learning of preschool aged children [9]. The present study aims at bridging the literature between EAL for preschool children and social justice education by using an action research design. The study employed the Montessori Method as one potential pedagogy that can be used. The results suggest that EAL for young learners can be successful when combined with the Montessori Method and social justice theory. This combination of educational theories resulted in an education that promoted student voice and gave the children autonomy over the education they received, while still maintaining a steady rate of language acquisition.

\section{Background}

As well as referring to changes in immigration and 
migration patterns, Giddens [1] defines globalization as an increase in interaction among people of varying social, cultural, and linguistic groups. This social trend impacts multiple facets of society. The perimeters set by Giddens in his discussion of globalization incorporate both the physical and nonphysical spaces used for such interactions. The increase of interaction among citizens of different regions, societies, and cultures has led to further concern, particularly in the educational sphere of society. The discussion now among practitioners and researchers of education is how a socially just education can be provided to groups of children who are a byproduct of the globalization trend. Considering the increase in English education, even in non-English speaking societies, this task is especially important since communication from the outset is the first obstacle that must be overcome when entering an English-speaking environment. The ability to communicate and understand one's new surroundings affects the overall education that non-English speaking children will receive.

How to effectively provide a socially just education for multicultural and multilinguistic groups of students is now becoming of fundamental importance. Social justice is a complicated theoretical concept that can have many meanings depending on the society and facet of society being discussed. In the case of social work, for instance, Olson, et al. [10] suggest that distributive justice can be defined as how services, goods, and opportunities are allocated in societies. For educational concerns of social justice, this definition may also apply if we view schooling and education as a service and a right of students. There is a difference between being provided with the right of receiving the service of education that is ensured by law and actively being able to participate in the education (service) that is being provided. Social justice can take on new meaning when examined in light of globalization trends. For Fraser [8], social justice requires equality and opportunity, but people must also be given the tools to take advantage of the opportunities provided so that they may participate fully in civic life. The task then becomes how to accomplish EAL learning with a focus on social justice as participation in education.

The how of 'doing' social justice has become a central concept among researchers and academics as a means of bridging the gap between theory of education and the practice of 'doing' education [11-14]. The research undertaken here is an exploratory piece of action research that sought to examine if the Montessori Method is an effective means by which to teach young EAL preschool children English while using a social justice platform. This is not to suggest that other pedagogies are not as equally beneficial in meeting the social justice needs of EAL students, but rather, that different pedagogies should be explored for different age groups in an effort to achieve the best socially just education possible.

Montessori [15-17], along with Dewey [18, 19] and Freire [20] recognized problems with traditional models of education. Montessori though, created a framework that can be implemented in schools, focusing on experiential learning and social justice. Like Dewey, Montessori believed that practical education should be valued as a means to influence society and change it where necessary [17]. By society, Montessori here is referring to all societies and the method of education needed to promote experiential learning is the same for all. Montessori, herself, states that her approach to education is not complete. Rather, the method she developed around experiential learning requires teachers to become observers in their classroom and act as experimentalists in the educational process [16]. The Montessori Method was chosen as the basis for this EAL program because of her focus on social justice and student voice within her framework. To Montessori, justice in education is a spiritual responsibility of the teacher so the child can reach his her full capabilities as a student and develop into a responsible spiritual being [17]. Montessori's definition of justice coincides with the need for social justice in EAL education outlined above. This method relies on teachers' abilities to 'listen' to each child through observation, respecting the voice of each child, and creating an individualized educational experience for each student.

Montessori assumed a homogeneous student group when writing about how language should be taught and learned. For EAL students, how second language learning occurs must also be considered. In EAL discourse, there have been suggestions of how language learning occurs most effectively through spoken language comprehension and reading $\backslash$ writing [21]. It is spoken language that gives rise to further opportunity in learning language. Once the foundations of a language have been learned, it is then that linguistic scaffolding should take place as a means to further the expressive language skills of the student. Word decoding is a struggle with language learning and is not determined by the age of the learner. Decoding can be understood as word recognition and comprehension [22]. Naturally, the age of the students will determine the extent to which the above definition is applied and expected. A useful tool when increasing the word decoding ability of young learners is to incorporate music and song into the lesson because music allows children to hear the language patterns, rhythm, and structure of a language [23]. Perhaps music, song, and circle time are less conventional models of conversation interaction, but they are important because they create connections between the words being heard and the meaning that the words convey, thus adding to the comprehension of the learner [24]. The research undertaken by Mistry \& Barnes [25] brings to light the necessity of providing EAL learners with linguistic models. Listening to educators and other pupils communicate gives English learners the opportunity to imitate the sounds being heard. The speaking of new vocabulary and hearing the new word being spoken often are very important to the child remembering the word. The need for such repetition has to do with how our memory works when language learning occurs. Repeating words and sentences allows for multiple opportunities for 
comprehension [26]. Although there is an acknowledgement that repetition within the lessons is extremely important, repetition between the lessons must also occur. In this study, these aspects of language development were used in conjunction with the Montessori Method and social justice framework.

\section{Methods}

Action research is not necessarily concerned with producing a new educational experience for students. Its primary concern is to improve practice that has already been established. There is no doubt that EAL programs have been established in schools and preschools throughout the English and non-English speaking world. What is needed, that has yet to be addressed, is the promotion of social justice within the system of EAL education, particularly at the preschool level. Action research seeks to improve practice and creates an environment conducive to democratic education. [27]. Action research can employ multiple methods, including qualitative and quantitative data sets. For this study, there were multiple methods employed (observation, field notes, checklists and parental surveys). Here though, the data from the checklists will be examined.

The study was conducted over a 14 -week period in a preschool in the Kanton of Zürich, Switzerland. A nonEnglish speaking environment was used in order to obtain the most accurate results of language development possible by minimizing outside influence of language exposure and acquisition. Prior to the beginning of the study, a meeting between the researcher and parents of the children took place, both in English and German, to ensure understanding of what the study hoped to achieve and what expectations were for the children and parents throughout the course of the study. Information sheets and consent forms were then distributed to parents and were made available in English and German. Efforts were made to ensure that each parent had access to German translation services when necessary so that all questions could be answered effectively and the study was understood fully. There was no limit on how many children were accepted into the lessons. The number of participants was determined by the willingness of parents to have his $\backslash$ her child $\backslash c h i l d r e n$ receive free English lessons. There were nine children who took part in the study, all varying in their previous exposure to English and multiple nationalities and ethnicities were represented. Each participant was assigned a name chosen by the researcher to ensure anonymity.

As discussed above, globalization (increased interaction between cultural, social, and linguistic groups) is becoming an ever more common phenomenon. In the group of nine participants who took part in this study, for instance, only two participants (Lara and Anna) were Swiss born and are siblings. They come from immigrant/migrant parents, the mother being Asian and the father originating from a nonEnglish speaking European country. The rest of the children were born outside of Switzerland. Two children came from
North American countries (one country officially bilingual, the other having one official language), three children were born in Asia, and two children were born in non-English speaking European countries. The reason for most of the immigration and migration was a direct result of employment of either one or both of the parents. Also, the time in which the children had been in Switzerland varied. Some were infants when they arrived and others were preschool aged. This, too, is a factor in the language development of each child.

The lessons occurred once a week and lasted between 30 and 40 minutes. Each lesson was planned using the Montessori Method for teaching language [16, 17]. Montessori presents a method that is not language specific. Her method can be applied to varying languages because the structures and parts of speech of every language are the same and the method for teaching is the same for each. Language learning and teaching was viewed in terms of development, instead of explicit teaching. [17]. Initially, the teaching of vocabulary used Montessori's outline for language lessons which consists of, firstly, associating the name with the object, secondly, assessment to ensure learning has occurred, and lastly, pronunciation of the name of the object [16]. This method for vocabulary development was used in each lesson; however, the researcher's involvement with the children was constantly monitored so that the children were able to learn English from their peers as well. The initial lesson, that being associating the name with the object, used varying methods that were chosen based on the interests, needs, and learning styles of the children. Once the name was established with a particular object, it was then that the researcher stepped back and allowed the children to learn through self-exploration, thus improving comprehension. The lessons themselves were planned using the Montessori Method with a focus on experiential learning in particular. The subject of each lesson was determined by the children's interests and learning styles, a particularly important part of the observation that Montessori stressed in her writings.

The role of the educator in the Montessori Method is integral to the learning process. The method she developed around experiential learning requires teachers to become observers in their classroom and act as experimentalists in the educational process [16]. Montessori viewed the observation of the child as fundamental to the development of her method. Montessori's observations were conducted in multiple school settings and in cultures throughout the world [28], which resulted in a method that can be applied to multiple societies, cultures, and linguistic groups. Observation should not be limited to the physical act of watching a child, but should include seeing the child's behavior, how helshe interacts with other children, how the child interacts with learning materials, and listening to the child's voice. One of the most unique features of the Montessori Method has to do with the role of the teacher and the autonomy that is afforded therein. Teachers should be 
provided with the opportunity to experiment in the school and in their classrooms [16]. Using this framework, educators should not be bound to a particular method by which to teach. Instead, the method should be determined by the students and the teacher's observations made throughout the teaching process. Here we can see the importance of student voice in how topics are learned.

Maria Montessori stresses the need for experiential learning throughout her writings, stating that intellectual development requires the use of the hands. Without such experiential learning the growth of the child is limited [17]. The stress, therefore, is placed on how children interact and manipulate the objects around them [16]. Again, we must return to the consideration of the age of each child. A child who is 2 years old will obviously not be expected to complete any work or manipulate structures in the same way as a 4-year-old. Although all of the children in this case were between the ages of 2 and 4 years, the physical abilities possessed by the children of different ages were noticeable and accommodations were made to suit each. The primary focus was not that each child could learn by 'doing' the same thing, but that they each learned by doing in whatever way they were able.

Experiential learning was at the forefront of thought in the planning and implementation of lessons. This was met with some difficulty throughout the project. Due to poor weather, most of the lessons, although still focusing on experiential learning, had to occur indoors. With that being said, it was of the utmost importance that each child was able to learn using his ไher hands and physical movement. A short summary of each of the fourteen lessons will serve to provide a comprehensive idea of the type of experiential learning that took place (see Table 1).

Table 1. Activities conducted during each Lesson.

\begin{tabular}{|c|c|}
\hline Lesson & Corresponding Activities \\
\hline 1 & $\begin{array}{l}\text { Singing circle/ Learning colors with balloons/ Verb practice } \\
\text { activity/ Singing circle }\end{array}$ \\
\hline 2 & $\begin{array}{l}\text { Singing circle/ Expanding color learning with new balloons/ } \\
\text { Hand measuring activity/ Singing circle }\end{array}$ \\
\hline 3 & $\begin{array}{l}\text { Singing circle/ Matching color activity/ Matching colors with } \\
\text { food/ Singing circle }\end{array}$ \\
\hline 4 & Singing circle/ Flower activity/ Nature walk/ Singing circle \\
\hline 5 & Singing circle/ Flower art activity/ Singing circle \\
\hline 6 & Singing circle/ Verb practice activity/ Singing circle \\
\hline 7 & Singing circle/ Calendar/ Station activities/ Singing circle \\
\hline 8 & Singing circle/ Making cookies/ Singing circle \\
\hline 9 & $\begin{array}{l}\text { Singing circle/ Calendar/ Reading time/ Station activities/ } \\
\text { Singing circle }\end{array}$ \\
\hline 10 & Singing circle/ Diwali lantern activity/ Singing circle \\
\hline 11 & $\begin{array}{l}\text { Singing circle/ Calendar/ Christmas market activity/ Singing } \\
\text { circle }\end{array}$ \\
\hline 12 & Singing circle/ Weather activity/ Singing circle \\
\hline 13 & $\begin{array}{l}\text { Singing circle/ Occupation drama (pilot, bus driver, teacher)/ } \\
\text { Singing circle }\end{array}$ \\
\hline 14 & $\begin{array}{l}\text { Singing circle Calendar/ Reading time/ Conversation practice/ } \\
\text { Singing circle }\end{array}$ \\
\hline
\end{tabular}

Each of the activities took advantage of the energy and the natural tendency for children to move, to create, and to explore. Of course, the amount of time spent on each activity was limited. It is unrealistic to expect a child to concentrate on one activity for 30-40 minutes. For this reason, two to three activities were chosen for each lesson period. If a child expressed interest in a particular activity, helshe was then given the option to continue with that activity. Most commonly, it was necessary to keep each activity to a maximum of fifteen minutes.

Teaching English to Speakers of Other Languages (TESOL) objectives [29] were used to monitor the progress of the participants because the objectives outlined are oriented to prekindergarten age children and can be used in conjunction with a variety of teaching pedagogies and methods. The TESOL standards coalesce with Montessori's pedagogy because students are encouraged to interact with language and are given the opportunity to demonstrate their language knowledge in multiple ways [29]. Each level from PreK-12 consists of five standards, spanning multiple school subjects. The standards include communication in language arts, mathematics, science, and social studies [29].

Each grade level includes areas of listening, speaking, reading, and writing for each standard and provides levels of proficiency spanning from one to five, one being beginner level and five being advanced, for each standard and for each objective therein. Only levels one to three were included for each area in the checklists for this study. The standards that were chosen focused on nonverbal comprehension during the beginning levels, which is an important consideration that must be made when previous exposure to English has been minimal. Verbal displays of English were encouraged as each child progressed. A checklist was made for each participant and was completed throughout the study period when objectives were met. At no time did the children see the checklists. They were completed after each lesson, away from the children so as to ensure that no unnecessary stress was being added to the learning process and to prevent the children from feelings of judgment in their education.

\section{Results}

Each child who participated in the study began meeting different TESOL outcomes. This is of great importance because it helped to identify where the children were beginning their English language journey. For example, Levin, Gabriel, and Elena come from homes where English is spoken in conjunction with at least two other languages. The other participants had very little or no previous exposure to English. The outcomes met during the first month of study varied from zero to six, and included mostly comprehension objectives with only some participants meeting oral language demonstrations (see Figure 1). 


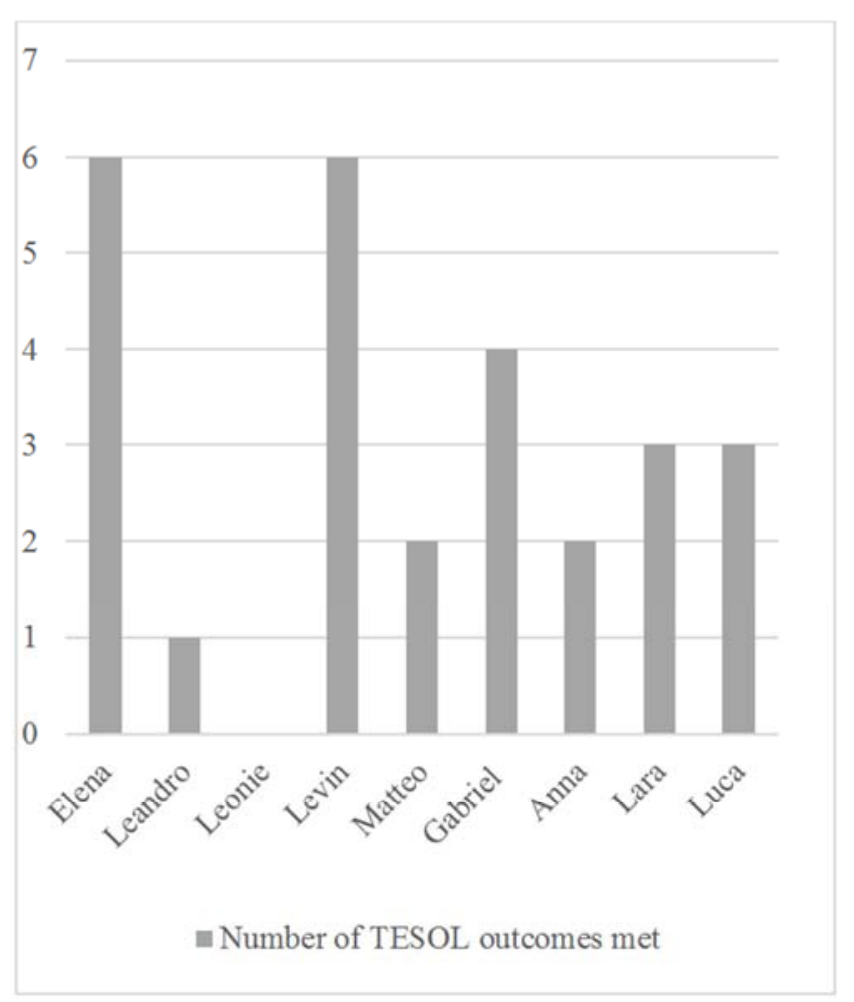

Figure 1. Month 1 TESOL Outcomes Met.

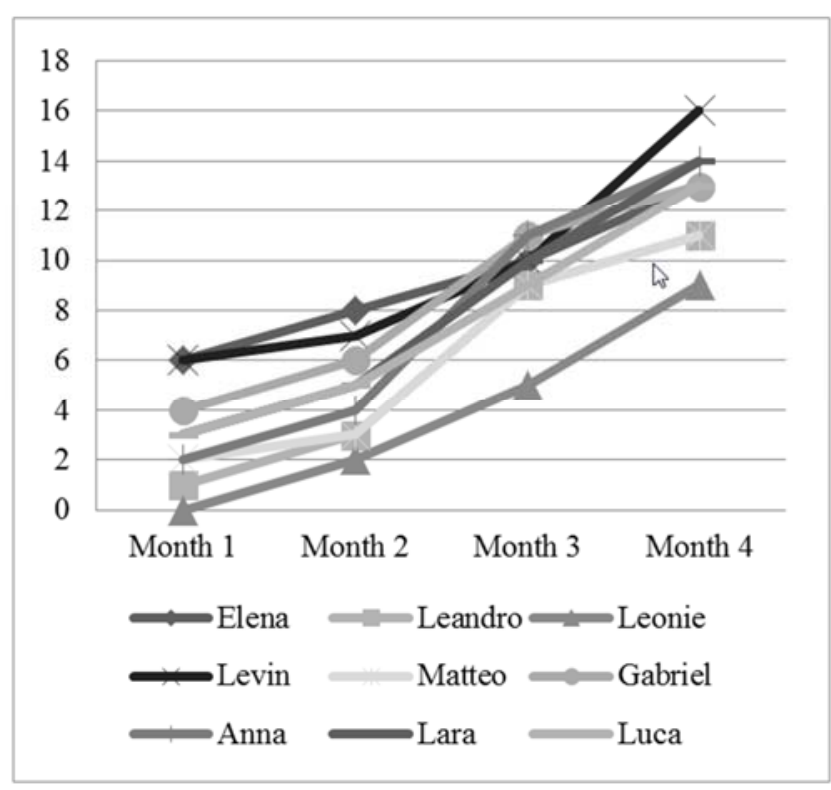

Figure 2. Months 1-4 TESOL Outcomes Met.

The following progress in months two and three saw a sharp increase in the outcomes being met (see Figure 2). The increase in comprehension showed dramatic growth during this time and the oral displays of English increased with most children. Between months one and two, the average increase in outcomes achieved across all standards was 1.78. The standards calculated did not include the proficiency levels (one to three) of standards. Seven children increased the outcomes met by two, while two of the children increased the outcomes met by one. Between months two and three is where the sharpest incline occurred. Here, the average outcomes increased from between two to seven, with the mean score being 4.56. Elena, Leonie, Levin, and Luca increased their objectives met by less than five, keeping with the overall average. Between months three and four the number of outcomes met is less dramatic. The average increase here is 3.44 and ranges between two and six. Each child ended the study increasing the TESOL English outcomes met by an average of 9.67. The minimum increase was Elena who increased by seven outcomes met and the maximum increase was Anna, with 12.

The sharp increase of outcomes met between months two and three largely occurred in the comprehension of the children and their ability to follow instructions. For instance, the use of polite expressions (please and thank you) was mastered by most children early in the study. With time, the abilities of the children expanded and they were able to make polite requests regularly and independently. Initially both the first language (L1) and second language (L2) were acceptable for communication. This is especially important when teaching young children. Each child must be given the freedom to communicate in whatever way helshe feels most comfortable. It was during the same time that most of the children could follow simple oral instructions. Between months two and three, this outcome was combined with the more advanced outcome of following multistep oral instructions. Scaffolding was used throughout to reiterate the vocabulary needed for both single step and multistep directions. Similarly, during the time between months two and three, most children moved beyond responding nonverbally to oral instructions and began identifying objects, orally demonstrating their English knowledge [29].

\section{Discussion}

The results show that even children who had no previous exposure to English showed evidence of language learning. The beginning outcomes for Leandro and Leonie are quite important here. Neither child had previous knowledge of English and experienced a silent period. Leandro's nonverbal period lasted until week nine and Leonie's lasted until week 12. Leandro came out of his non-verbal stage slowly, with new words and phrases being added to his vocabulary weekly, while Leonie came out of her non-verbal period suddenly, having an unexpected outburst of oral language use in week 12. As each of the children began to feel more comfortable in the learning environment, their oral demonstrations began to increase. Although there were no such expectations placed on any of the children, Elena and Lara were particularly vocal in their English and by the end of the study were making word chunks to convey meaning. The following sentences demonstrate the type of word chunking that occurred:

Lara: And where is cloud?

Elena: Mouse. Mouse crying sad.

Elena: Elena umbrella it rains. 
The above sentences demonstrate the advancement of these two children even though Elena had a small amount of previous English exposure, while Lara had none. Other children, such as Levin and Gabriel, who also had previous exposure to English, could engage in conversation, but had not reached the same level of word chunking. Luca and Leonie, having no prior knowledge of English, could answer questions directed toward them, but could not, at this point, engage in initiating conversation in English, beyond making requests, using one or two words to do so.

The levels of English, both comprehension and spoken, of each of the children varied throughout the study. Each child made similar progress each month, increasing their comprehension, vocabulary knowledge, and attempts at spoken English. The environment created was largely based on respect for the child and their language progression, keeping the cultural, social, and linguistic backgrounds of the participants and the principles of social justice in mind throughout.

Learner voice is perhaps one of the most important foundations for creating a socially just educational experience. The application of social justice theory to teaching young children EAL is complicated for two main reasons. First, the linguistic skills need to be provided to allow learners to have a voice. Secondly, the students then must actively use that voice in helping to shape the education being provided. The result is a sense of independence and freedom to communicate and express oneself in multiple and varied ways [17]. This type of pedagogy is difficult to establish when children have not developed the language skills needed to express themselves. 'Help, yes, and no' were words taught early in the study so children who did not experience a silent period could convey their wishes or like/dislike of something. The beginning of the study was based on activities that the researcher chose and implemented using the Montessori Method. By the third lesson, the level of comprehension of the participants was such that the researcher could suggest ideas for the following lesson and the children could then indicate with a 'yes' or 'no' whether they liked the idea or not. For Leonie and Leandro, head movements were encouraged to convey their wishes during their silent periods. Teaching the word 'help' in particular, was strategic. It allowed each of the children to communicate need and it also gave them a tool with which they could voice displeasure with something or someone, thus minimizing frustration. It helped to promote regulating emotions, an important developmental milestone regardless of language. It was then that the class dynamics changed where the teacher and students became more equal in the classroom [30]. It was also during this time that the researcher began to take on the role of a leader as opposed to the authority in the classroom [18].

The limitations for this piece of action research lay in the sample size. The participants in this study consisted of nine children. Ideally, further research could include a larger sample size and the study period would be much longer than what was able to occur here. Another limitation has to do with the TESOL checklist used. The outcomes outlined in the checklists focused primarily on comprehension and nonverbal responses to language. It did not measure the progress of spoken language. For instance, the instances of word chunking provided above are not distinguished with one or two word answers that are provided by other participants. The ability to respond is the focus, not on the level of English used in the response. This allows for some English development that is not reflected in the data provided by the checklists. There are no checklists that are prefect and reflect every language development stage experienced by every child. In conjunction with any checklists used, field notes should be used as well, to produce a complete idea of how each child learns and at what rate.

\section{Conclusion}

Developing and exploring new pedagogies has particular importance for young EAL students who have little voice in the education they receive and in the immigration or migration of their parents andlor families. With the rise in globalization, social justice has taken an even more important role in education. Until this point, the majority of the education being discussed, has been limited to primary, secondary, and post-secondary students. With more families immigrating and migrating, young children must now be included within this educational discourse. The conclusions that can be drawn from the data collected here indicate that even when children do not live in an English-speaking country, employing the Montessori Method can have positive results for English language learning. The goal of the study was to provide a means of 'doing' social justice in language education that respected the children as valued contributors to their educational experience while making education accessible to educators. Although this is a first step for educators and researchers, it does open the door for further research to occur.

\section{Acknowledgements}

I would like to thank my supervisor, Jo Warin, who offered tremendous support and guidance throughout the study.

\section{References}

[1] Giddens, A. 2002. Runaway World: How Globalisation is Reshaping our Lives. New ed. London: Profile Books Ltd.

[2] Held, D. 2010. Cosmopolitanism: Ideals and Realities. Cambridge: Polity Press.

[3] Buchwalter, A. (ed.). 2012. Hegel and Global Justice. Dordrecht: Springer.

[4] Held, D. 2008. Globalization, Corporate Practice and Cosmopolitan Social Standards. In A. Kuper (ed.), Global Responsibilities: Who Must Deliver on Human Rights?, 185204. New York: Routledge. 
[5] Appadurai, A. 1999. Globalization and the research imagination. International Social Science Journal, 51(160): 229-238.

[6] Hallett, C. and Prout, A. (eds.). 2003. Hearing the Voices of Children: Social Policy for a New Century. London: RoutledgeFalmer.

[7] James, A. January 2011. To Be (Come) or Not to Be (Come): Understanding Children's Citizenship. The Annals of the American Academy of Political and Social Science, 633: 167179.

[8] Fraser, N. 2007. Re-framing justice in a globalizing world. In T. Lovell (ed.), (Mis)recognition, Social Inequality and Social Justice, 17-35. London: Routledge.

[9] Herschensohn, J. and Young-Scholten, M. (eds.). 2014. The Cambridge Handbook of Second Language Acquisition. Enhanced Credo ed. Cambridge, UK: Cambridge University Press.

[10] Olson, C. J., Reid, C., Threadgill-Goldson, N., Riffe, H.A., and Ryan, P.A. January 2013. Voices From the Field: Social Workers Define and Apply Social Justice. Journal of Progressive Human Services, 24 (1): 23-42.

[11] Arshad, R., Wrigley, T., and Pratt, L. (eds.). 2012. Social Justice Re-examined: dilemmas and solutions for the classroom teacher. Stoke-on-Trent: Trentham Books Ltd.

[12] Rojanapanich, P. and Pimpa, N. 2011. Creative Education, Globalization and Social Imaginary. Creative Education, 2 (4): 327-332.

[13] Smith, E. 2012. Key issues in education and social justice. London: SAGE.

[14] Unterhalter, E. 2008. Cosmopolitanism, Global Social Justice and Gender Equality in Education. Compare: A Journal of Comparative Education, 38 (5): 539-553.

[15] Montessori, M. 2004. The Discovery of the Child. Delhi, India: Aakar Books.

[16] Montessori, M. 2006. The Montessori Method. New York, NY: Cosimo Classics.

[17] Montessori, M. 2007. The Absorbent Mind. Radford, VA: Wilder Publications.

[18] Dewey, J. 1997. Experience and Education. New York: Touchstone.
[19] Dewey, J. 2008. Democracy and Education: An Educational Classic. Radford, VA: Wilder Publications.

[20] Freire, P. 1996. Pedagogy of the Oppressed, trans. M. Bergman Ramos. New Rev ed. London: Penguin.

[21] Riley, J., Burrell, A., and McCallum, B. October 2004. Developing the spoken language skills of reception class children in two multicultural, inner- city primary schools. British Educational Research Journal, 30 (5): 657-672.

[22] Chen, X., Geva, E., and Schwartz, M. 2012. Understanding literacy development of language minority students: an integrative approach. Reading and Writing, 25(8): 1797-1804.

[23] Brouillette, L. 2012. Supporting the Language Development of Limited English Proficient Students through Arts Integration in the Primary Grades. Arts Education Policy Review, 113 (2): 68-74.

[24] del Pilar García Mayo, M. and Alcón Soler, E. 2013. Negotiated input and outputlinteraction. In J. Herschensohn and M. Young-Scholten (eds.), The Cambridge Handbook of Second Language Acquisition, 209-229. Cambridge, UK: Cambridge University Press.

[25] Mistry, M. and Barnes, D. 2013. The use of Makaton for supporting talk, through play, for pupils who have English as an Additional Language (EAL) in the Foundation Stage. Education 3-13, 41(6): 603-616.

[26] Tabors, P. O. 2008. One Child, Two Languages: A Guide for Early Childhood Educators of Children Learning English as a Second Language. 2nd ed. Baltimore, Maryland, U.S.A.: Paul H. Brookes Publishing Co.

[27] Cohen, L., Manion, L., and Morrison, K. 2011. Research Methods in Education. 7th ed. London: Routledge.

[28] Helfrich, M. S. 2011. Montessori Learning in the 21st Century: A Guide for Parents and Teachers. Troutdale, Oregon: NewSage Press.

[29] Gottlieb, M., Carnuccio, L.M., Ernst-Slavit, G., and Katz, A. 2006. PreK-12 English Language Proficiency Standards. Mattoon, Illinois, U.S.A.: Teachers of English to Speakers of Other Languages International, Inc.

[30] Barakett, J. and Cleghorn, A. 2008. Sociology of Education: An Introductory View From Canada. 2nd ed. Toronto: Pearson Prentice Hall. 